\title{
Diversification and firm performance in China
}

\author{
Hao Shen ${ }^{1}$, Dong Wang ${ }^{2}$ and Zhongfeng Su ${ }^{3 *}$ \\ ${ }^{1}$ School of Management, Xi'an Jiaotong University, Xi'an, 710049, Shaanxi. P. R. China. \\ ${ }^{2}$ Media Management School, Communication University of China, Beijing, 100010, P. R. China. \\ ${ }^{3}$ School of Business, Nanjing University, Nanjing, 210093, Jiangsu, China.
}

\begin{abstract}
Accepted 24 August, 2011
This study focuses on the performance implication of diversification in China. It finds that product diversification has an inverse U-shaped relationship with firm performance, while geographic diversification has a U-shaped one. In addition, the interaction between product diversification and geographic diversification has a negative impact on firm performance. The findings not only enrich our knowledge of the value of diversification in China's transition economy, but also guide Chinese firms on how to use diversification strategy to compete in the market and enhance their performance.
\end{abstract}

Key words: Diversification, performance, China.

\section{INTRODUCTION}

Does diversification contribute to or inhibit firm performance? This is one of the most important but inconclusive questions in strategic management research (Li and Wong, 2003). Concerning the performance implication of diversification in China, there are conflicting perspectives on it. Some scholars argue that diversification has a positive impact on firm performance in China since it is a critical tool to cope with the uncertainties caused by China's institutional transitions (Peng, 2003). However, others argue that most Chinese firms are resource-lacking ( $\mathrm{Li}$ et al., 2005; Su et al., 2009), and they can hardly fit the resource commitments of diversification. Moreover, diversification increases the costs of control and coordination within the firm (Wiersema and Bowen, 2008). Thus, they argue that diversification has an adverse impact on firm performance in China. Herein, the impact of diversification on firm performance in China is still unclear.

In this study, we suggest that the conflicting perspectives on the performance implication of diversification in China are due to two reasons. First, diversification is, at least in part, driven by the institutional framework, and the institutional environment can impact the efficacy of diversification (Delios et al., 2008; Peng and Delios, 2006). China's institutional transitions, which have changed

*Corresponding author. E-mail: zhongfengsu@163.com. the formal and informal rules of the game fundamentally and comprehensively (Peng, 2003), lead to China present some specific characters, such as resource lacking, the fragmentation of domestic markets, and high uncertainty in the market (Meyer, 2008; Su et al., 2009). These characters have significant impacts on the value of diversification. Thus, they must be taken into consideration when investigating the performance implication of diversification in China.

Secondly, as two key dimensions of diversification, product diversification and geographic diversification function diversely (Delios and Beamish, 1999; Peng and Delios, 2006). Yet, "most current research either focuses on product diversification (often under the 'strategic management' label) or geographic diversification (usually under the 'international business' label). Scholars rarely address how these two strategies interact" (Peng and Delios, 2006: 386). Since product diversification and geographic diversification often interact with each other to influence firm performance (Hitt et al., 1997), there is a need to investigate them synchronously, especially their interaction (Delios and Beamish, 1999; Hitt et al., 1997).

The purpose of this article, therefore, is to probe deep into the performance implication of diversification in China by taking above two reasons into consideration. To realize the research objective, we first identify China's specific characters which affect the value of diversification. Then, we hypothesize the performance effects of product diversification, geographic diversification, and 
their interaction. Third, we empirically test our hypotheses. Finally, we discuss our contributions, limitations, and future directions.

Several contributions fuel this study. First, by taking China's specific characters caused by institutional transitions into account, this study deepens our knowledge of the performance implication of diversification during China's institutional transitions. Second, this study not only tests the impacts of product diversification, geographic diversification, and their interaction on firm performance synchronously, which provides an in-depth understanding on the value of diversification. Finally, the study also has important application value as it can inform mangers the proper choice of diversification strategy.

\section{LITERATURE REVIEW AND HYPOTHESES DEVELOPMENT}

\section{Diversification and firm performance}

Diversification, which refers to the scope of the firm (Peng and Delios, 2006), is one of the most important topics in strategy management research. Extant literature documents that product diversification and geographic diversification can characterize expansions and scope of a firm's business in the market (Wiersema and Bowen, 2008), thus product diversification and geographic diversification have been well acknowledged as the two key dimensions of diversification. Product diversification refers to the relatedness of the firm's products, or the extent to which a firm's different lines of business or industries are linked (Tongli et al., 2005), and geographic diversification reflects the extent to which a firm operates its business involving in different regions which includes similar cultures, customer needs, living standards, and levels of economic development (Qian et al., 2008).

With regard to the impact of diversification on firm performance, existing studies have posited that diversification itself have specific advantages or disadvantages that can beyond the characteristics of the firm and the market environment in which it operates (Dastidar, 2009). Several theories have been taken to investigate the performance implication of diversification. Yet, these theories can hardly give out a consentaneous conclusion. For example, the transaction cost theory indicates diversification increases the costs of coordination and control over a firm's activities, and these costs barrier to improve performance by expand business in product scopes or in geographic regions (Wiersema and Bowen, 2008). However, diversification can also share the managerial costs of transportation, communication, and distribution within the market, which reduces the transaction cost and improve firm performance (Qian et al., 2010; Grant, 1987). Herein, the transaction cost theory does not give a consistent conclusion on the relationship between diversification and firm performance.

The resource-based view is another theory used to investigate the performance implication of diversification. Some researchers emphasize that diversification provides the opportunity to leverage the firm's resources via various products or different geographic regions (Wiersema and Bowen, 2008; Thomas and Eden, 2004), which can advance firm performance. In contrast, others argue that the resources, which provide the most benefit to a diversified firm, are difficult to transfer between different regions and can hardly be used for different products (Fang et al., 2007). If the firm tries to transfer such key resources for the purpose of diversification, it will damage firm performance (Dastidar, 2009). Thus, the resource-based view does not provide a uniform result on the diversification-performance linkage as well.

Besides diversities in theoretical conclusions, the empirical findings are also inconclusive. For example, Tongli et al. (2005) find that product diversification is negatively correlated to performance, while geographic diversification is positively associated with performance; Delios et al. (2008) indicate that product diversification can increase firm performance; Qian et al. (2010) find that geographic diversification enhances firm performance linearly up to a certain threshold, and then its impact becomes negative.

Regarding the competing perspectives and empirical findings on the relationship between diversification and firm performance, we argue that there are two possible explanations. First, the performance implication of diversification is influenced by the institutional environment. Diversification is, at least in part, driven by the institutional framework, and the institutional environment can impact the efficacy of diversification (Delios et al., 2008; Peng and Delios, 2006). Several studies have supported it. For example, Wan and Hoskisson (2003) find that product diversification is negatively related to firm performance in more munificent institutional environments, but positively related in less munificent institutional environments. Chakrabarti et al. (2007) find that diversification negatively impacts performance in developed institutional environments. Thus, the institutional environment should be taken into account when investigate the value of diversification.

Second, product diversification and geographic diversification should be examined synchronously. In extant research, product diversification and geographic diversification "have often remained separate from one another. Seldom have researchers looked at the twin issues of whether, and how product and geographic scope interact with one another" (Peng and Delios, 2006: 387). Yet, product diversification and geographic diversification often interact with each other to influence firm performance (Hitt et al., 1997). Thus, it is of importance to investigate them synchronously, especially their interaction (Delios and Beamish, 1999; Hitt et al., 1997). 
Based on the afore reasons, to probe deep into the performance implication of diversification in China, this study will investigate how product diversification, geographic diversification, and their interaction impact firm performance through taking China's institutional environment as a key research context. Since China's institutional environment is the key research context, before developing hypotheses, we will briefly introduce China's institutional transitions.

\section{China's institutional transitions}

During the past three decades, to improve productivity and efficiency of the economy, China has reformed its economic system from central planning to market competition (Su et al., 2009). China's institutional transitions lead to China present a specific institutional condition with three significant characters: resource lacking, the fragmentation of domestic markets, and high uncertainty in the market (Meyer, 2008; Su et al., 2009).

First, due to the weak financial market infrastructure, it is often difficult for Chinese firms to gain resources in the market (Khanna and Palepu, 2000). In addition, most Chinese firms often have relatively less sophisticated technologies and little marketing experience (Hitt et al., 2000; Li et al., 2005). And, they usually lack skilled managers and experiences to compete in the market (Peng et al., 2004). As a result, the institutional transitions result in resource lacking being a significant character of Chinese firms.

Second, "today, China is one country but many economies" (Meyer, 2008: 3). China decentralized much of its economy save by the early 1980 s, and the downside of decentralization was that China evolved into several geographic economies (Meyer, 2008). In addition, Chinese provinces compete for GDP growth and erect barriers to inter-provincial trade ( $\mathrm{Li}$ and Zhou, 2005). The combination of local GDP targets and local protectionism lead to Chinese markets remain local rather than national. Thus, the fragmentation of domestic markets becomes the second significant character of China's transition economy (Meyer, 2008).

Finally, compared with firms in developed market, Chinese firms are distinctive in terms of operating in a much more uncertain environment (Su et al., 2009). China's institutional transitions have changed the market environment dramatically. On one hand, market competition has grown from nonexistent to increasingly intense (Tan and Peng, 2003); on the other hand, institutional transitions have changed the formal and informal "rules of the game" fundamentally and comprehensively (Peng, 2003). Thus, while firms in developed economies do experience some environmental uncertainties, the scale and scope of such uncertainties pale in comparison with those suffered by Chinese firms(Peng, 2003; Wright et al., 2005).

In summary, China's institutional transitions result in its institutional environment exhibit three characters: resource lacking, the fragmentation of domestic markets, and high uncertainty in the market (Meyer, 2008; Su et al., 2009). These characters have strong impact on the relationship between diversification and firm performance in that the value of diversification depends on institutional condition (Delios et al., 2008). Thus, we will take them into consideration to investigate the performance implication of diversification in China.

\section{Hypotheses development}

China's institutional transitions make its market environment embodies high uncertainties (Peng, 2003), which leads to Chinese firms take product diversification as a strategic response to these uncertainties (Nachum, 1999). Product diversification is beneficial to attract consumers, satisfy differentiate needs, and establish brand image. Thus, product diversification make the firm be possible to acquire prior performance against its rivals. In addition, through diversifying their products, the firm can rapidly seize the market share and enhance sale returns by satisfying various market demands. Thus, product diversification contributes to firm performance.

However, product diversification also needs significant resource commitments (Wiersema and Bowen, 2008). Implementing a diversified product strategy not only needs large investments to commercialize diversified products, but also increases bureaucratic costs to govern design, R\&D, production, and marketing of diversified products (Thomas and Eden, 2004). The amount of resources available to a firm is limited and scarce in China's transition economy (Su et al., 2009). Thus, when a firm's product diversification is at a high level, it is hardly able to satisfy the resource requirement of product diversification. As a result, the scarcity of resources places a real constraint on product diversification. In addition, high product diversification results in greater additional costs of control and coordination to avoid the competition on the resources among different products (Delios et al., 2008).

Meanwhile, rapid change in customer needs in transitional environments leads to high product diversification do not match relatively efficient product markets perfectly (Chakrabarti et al., 2007), causing relative wasted costs. Thus, although product diversification is a critical tool for Chinese firms to cope with the uncertainties caused by institutional transition, a high level product diversification is possible to cause the additional cost exceed the incremental benefits associate with product diversification. Therefore,

$\mathrm{H}_{1}$ : Product diversification has an inverted U-shaped relationship with firm performance in China

Regarding the relationship between geographic diversification and firm performance, we argue it is U-shaped in 
China. When geographic diversification is low, the firm only operates in a few regions. It can devote all the resources to such a few regions. Thus, it will be much familiar with these geographic markets, be sensitive to the market changes, and have more knowledge on the local customers (Fang et al., 2007). Also, it is able to adapt to the market changes and to grasp the new opportunities and demands in the market quickly (Qian and $\mathrm{Li}, 2002)$. In addition, the costs of control and coordination among different regions are low (Nachum, 1999). Moreover, the firm does not need to deal with the fragmentation of domestic markets. Therefore, when the geographic diversification is at a low level, the firm has a better performance.

When geographic diversification is high, the firm can successfully decentralize the risks of significant changes in a region (Grant, 1987). In addition, high geographic diversification aids in realizing the economies of scale (Qian et al., 2010). Although the fragmentation of domestic markets results in a high cost, geographic diversification reduces "the managerial costs of coordination, transportation, communication, and distribution across different regions" (Qian et al., 2010). Thus, high geographic diversification also contributes to firm performance in China.

However, the performance of a firm with medium level geographic diversification is not so wonderful. Compared with the low geographic diversification firm, the medium level geographic diversification firm is less familiar with the geographic markets, is less sensitive to the market changes, and has less knowledge on the local customers. Moreover, because it suffers the fragmentation of domestic markets, it has more costs of control and coordination.

Thus, its performance will be weaker than the low geographic diversification firm. Compared with the high geographic diversification firm, the medium level geographic diversification firm is incapable of decentralizing the risks and achieving the economies of scale. Thus, its performance will also be lower. As a result, the performance of the medium level geographic diversification firm is weaker than those of the low and high geographic diversification firm:

$\mathrm{H}_{2}$ : Geographic diversification has a U-shaped relationship with firm performance in China.

Although both product diversification and geographic diversification are important for firm performance, taking them synchronously is not proper for Chinese firms. Diversification needs a strong resource commitment (Wiersema and Bowen, 2008). Given the insufficient resources of Chinese firms owned, they often have trouble satisfying the resource requirement of diversification. If a firm takes both product diversification and geographic diversification synchronously, it can provide sufficient resources to none of them. In addition, the firm will suffer the competition on the resource, which will seriously will seriously increase the costs of control and coordination (Hitt et al., 1997). Therefore, taking product diversification and geographic diversification synchronously impedes firm performance in China:

$\mathrm{H}_{3}$ : The interaction of product diversification and geographic diversification has a negative effect on firm performance in China.

\section{METHODOLOGY}

\section{Sample}

Archival data of listed firms are more accessible and external than case or survey data typically used in many previous China studies (Su et al., 2009). Thus, the sample is composed of publicly held firms draw from the China Stock Market Accounting Database (CSMAR). CSMAR is one of the most famous databases in China, and it contains the information of firms whose stock is traded on the Shanghai or Shenzhen stock exchanges.

In this study, 200 firms are randomly selected from the electronics industry and pharmaceutical industry. Such two industries are taken for two reasons: the diversification is general in these industries and they can avoid the bias caused by a single industry. All the data come from their 2007 annual reports. To ensure that there is no systematic sampling error, the sample is compared with other firms in the database along major attributes such as firm size, age, and sales using t-tests. All t-statistics are insignificant, suggesting little evidence of sampling error.

\section{Variables}

Diversification can be measured by the Herfindahl index approach (Acar and Sankaran, 1999; Hill and Hansen, 1991). Thus, the Herfindahl index is employed to calculate product diversification and geographic diversification in this study. Accounting-based measures are well acknowledged as possible indicators of firm performance (Qian et al., 2008). Based on prior research, return on equity (ROE) is used to measure performance (Palepu, 1985; Ramaswamy et al., 2004). Both firm size and firm age have important impacts on firm performance, thus, they are taken as control variables. Firm size is measured by the natural logarithm of number of employees (Su et al., 2009). In addition, industry is controlled as dummy variable (electronics industry $=0$ and pharmaceutical industry $=1$ ).

\section{FINDINGS}

The descriptive statistics are shown in Table 1. The regression model is used to test the hypotheses. The results are shown in Table 2. Model 2 presents that there is a significant inverse U-shaped relationship between product diversification and firm performance $(\beta=-0.114$, $p<0.05$ ), which supports $\mathrm{H}_{1}$. Concerning the impact of geographic diversification on performance, the result of Model 3 indicates it is U-shaped $(\beta=0.288, p<0.001)$. Thus, $\mathrm{H}_{2}$ is also supported. Finally, the interaction of product diversification and region diversification is taken into the Model 4 to test $\mathrm{H}_{3}$. From the regression result, we can find that the interaction has a negative effect on firm performance. Thus, $\mathrm{H}_{3}$ is supported as well. 
Table 1. Descriptive statistics and correlation matrix.

\begin{tabular}{lccccc}
\hline Variable & $\mathbf{1}$ & $\mathbf{2}$ & $\mathbf{3}$ & $\mathbf{4}$ & $\mathbf{5}$ \\
\hline Firm size & 1 & & & & \\
Firm age & $0.207^{\star *}$ & 1 & & & \\
Product diversification & $-0.145^{\star}$ & $-0.154^{*}$ & 1 & & \\
Geographic diversification & 0.016 & -0.125 & -0.074 & 1 & \\
Firm performance & -0.055 & $-0.258^{* *}$ & -0.009 & 0.059 & 1 \\
Means & 11.73 & 10.60 & 1.84 & 2.28 & 9.01 \\
St. D. & 0.85 & 4.47 & 0.85 & 1.18 & 10.35 \\
\hline
\end{tabular}

* Significant at $5 \%$; * Significant at $1 \%$.

Table 2. Results of regression analysis.

\begin{tabular}{|c|c|c|c|c|}
\hline Variable & Model 1 & Model 2 & Model 3 & Model 4 \\
\hline Firm size & -0.089 & -0.097 & -0.088 & $-0.114^{+}$ \\
\hline Firm age & $-0.399^{* * *}$ & $-0.393^{\star * *}$ & $-0.391^{\star \star *}$ & $-0.369^{* \star *}$ \\
\hline Industry & 0.009 & -0.002 & 0.024 & 0.051 \\
\hline Product diversification (PD) & & 0.049 & & 0.060 \\
\hline$P D \times P D$ & & $-0.114^{*}$ & & $-0.142^{\star *}$ \\
\hline Geographic diversification (RD) & & & $-0.161^{\star}$ & $-0.193^{\star *}$ \\
\hline$R D \times R D$ & & & $0.288^{* * *}$ & $0.256^{\star * *}$ \\
\hline$P D \times R D$ & & & & $-0.198^{\star * *}$ \\
\hline $\mathrm{R}^{2}$ & 0.185 & 0.197 & 0.235 & 0.272 \\
\hline F-value & $6.245^{\star * *}$ & $4.205^{\star \star \star}$ & $4.059^{\star * *}$ & $3.055^{\star * *}$ \\
\hline
\end{tabular}

${ }^{+}$Significant at 10\%; * Significant at $5 \%$; ** Significant at $1 \%$; ${ }^{* * *}$ Significant at $1 \%$.

\section{DISCUSSION AND CONCLUSION}

\section{Contributions}

Two theoretical contributions fuel this study. First, through taking China's special institutional conditions into account, this study enriches our knowledge of the performance implication of diversification in China. Extant research indicates that diversification is, at least in part, driven by the institutional framework and the institutional environment can impact the efficacy of diversification (Delios et al., 2008; Peng and Delios, 2006). Thus, to probe deep into the performance effect of diversification, it is necessary to take China's institutional context in to consideration. In this study, we identify three Chinese specific characters caused by its institutional transitions: resource lacking, the fragmentation of domestic markets, and high uncertainty in the market (Meyer, 2008; Su et al., 2009). Then, we investigate the performance effect of diversification in the context with these three characters. The study finds that product diversification has an inverted U-shaped effect on firm performance, geographic diversification has a U-shaped one, and the interaction of them has a negative impact on firm performance. Second, this study improves our understanding of the value of diversification. In extant research, product diversification and geographic diversification "have often remained separate from one another. Seldom have researchers looked at the twin issues of whether and how product and geographic scope interact with one another" (Peng and Delios, 2006: 387). Yet, product diversification and geographic diversification often interact with each other to influence firm performance (Hitt et al., 1997). Thus, it is of importance to investigate them synchronously, especially their interaction (Delios and Beamish, 1999; Hitt et al., 1997). This study not only tests the impacts of product diversification and geographic diversification on firm performance respectively, but also explores the value of their interaction. By this way, this research provides an improved knowledge about the relationship between diversification and performance.

\section{Management implications}

Besides theoretical values, this study also has important application value as it informs Chinese mangers the proper choice of diversification strategy. First, the inverse U-shaped relationship product diversification and firm performance suggests that Chinese firms should take a medium level product diversification strategy. Although 
product diversification is a strategic response to market uncertainties, the scarcity of resources in Chinese firms places a constraint on product diversification. Second, the U-shaped relationship geographic diversification and firm performance suggests that both a low level and a high level geographic diversification contribute more to firm performance. Finally, the negative effect of the interaction of product diversification and geographic diversification indicates that Chinese firms should take product diversification strategy, or geographic diversification strategy, rather than both of them synchronously.

\section{Limitations}

Despite its novel contributions, this study also has some limitations. The findings are context- specific and should be viewed cautiously when generalized to other contexts. Although the study has been very tentative regarding its generalizability to other settings, there are theoretical reasons to believe that firms in other emerging economies may experience similar dynamics. This speculation needs to be validated by future research. Moreover, the archival data used in the study may discount any causal statements being supported by empirical findings. Thus, longitudinal approach is needed in future studies.

\section{AKNOWLEDGEMENT}

This study is supported by the Philosophic and Social Science Foundation of Education Department of Jiangsu Province, P. R. China (2011SJD630012) and the Humanities and Social Sciences Research Foundation from the Ministry of Education of China (11YJC630184).

\section{REFERENCES}

Acar W, Sankaran K (1999). The myth of the unique decomposability: specializing the Herfindahl and entropy measures? Strategic Manage. J., 20(10): 969-975.

Chakrabarti A, Singh K, Mahmood I (2007). Diversification and performance: Evidence from east asian firms. Strategic Manage. J., 28: 101-120.

Dastidar P (2009). International corporate diversification and performance: does firm self-selection matter. J. Int. Bus. Stud., 40: 71-85.

Delios A, Xu D, Beamish PW (2008). Within-country product diversification and foreign subsidiary performance. J. Int. Bus. Stud., 39: 706-724.

Delios A, Beamish PW (1999). Geographic scope, product diversification, and the corporate performance of Japanese firms. Strategic Manage. J., 20: 711-727.

Fang Y, Wade M, Delios A, Beamish PW (2007). International diversification, subsidiary performance and the mobility of knowledge resources. Strategic Manage. J., 28: 1053-1064.

Grant RM (1987). Multinationality and performance among British manufacturing companies. J. Int. Bus. Stud., 18(3): 79-89.

Hill CWL, Hansen GS (1991). A longitudinal study of the cause and consequences of changes in diversification in the U.S. pharmaceutical industry 1977-1986. Strategic Manage. J., 12: 187-199.
Hitt MA, Dacin MT, Levitas E, Arregle JL, Borza A (2000). Partner selection in emerging and developed market contexts: resourcebased and organizational learning perspectives. Acad. Manage. J., 43(3): 449-467.

Hitt MA, Hoskisson RE, Kim H (1997). International diversification: effects on innovation and firm performance in product-diversified firms. Acad. Manage. J., 40: 767-798.

Khanna T, Palepu K (2000). The future of business groups in emerging markets: long-run evidence from Chile. Acad. Manage. J., 43(3): 268285.

Li M, Wong Y (2003). Diversification and economic performance: an empirical assessment of Chinese firms. Asia Pacif.u8u6 J. Manage., 20(2): 243-265.

Li H, Zhang Y, Chan TS (2005). Entrepreneurial strategy making and performance in China's new technology ventures: the contingency effect of environments and firm competences. J. High Tech. Manage. Res., 16: 37-57.

Li H, Zhou L (2005). Political turnover and economic performance: the incentive role of personnel control in China. J. Public Econ., 89: 1743-1762.

Meyer MW (2008). China's second economic transition: building national markets. Manage. Org. Rev., 4(1): 3-15.

Nachum L (1999). Diversification strategies of developing country firms. J. Int. Manage., 5(2): 115-140.

Palepu K (1985). Diversification strategy, profit performance and the entropy measure. Strat. Manage. J., 6: 239-255.

Peng MW (2003). Institutional transitions and strategic choices. Acad. Manage. Rev., 28(2): 275-286.

Peng MW, Delios A (2006). What determines the scope of the firm over time and around the world? An Asia Pacific perspective. Asia Pacif. J Manage., 23: 385-405.

Peng MW, Tan J, Tong TW (2004). Ownership types and strategic groups in an emerging economy. J. Manage. Stud., 41(7): 1105-1129.

Qian G, Khoury TA, Peng MW, Qian Z (2010). The performance implications of intra-and inter-geographic geographic diversification. Strategic Manage. J., 31: 1018-1030.

Qian G, Li J (2002). Multinationality, global market diversification and profitability among the largest US firms. J. Bus. Res., 55(4), 325-335.

Qian G, Li L, Li J, Qian Z (2008). Geographic diversification and firm performance. J. Int. Bus. Stud., 39: 197-214.

Ramaswamy K, Li M, Petitt BSP (2004). Who drives unrelated diversification? A study of Indian manufacturing firms. Asia Pacif. J. Manage., 21(4): 403-423.

Su Z, Xie E, Li Y (2009). Organizational slack and firm performance during institutional transitions. Asia Pacific J. Manage., 26: 75-91.

Tan J, Peng MW (2003). Organizational slack and firm performance during economic transitions: two studies from an emerging economy. Strategic Manage. J., 24: 1249-1263.

Thomas DE, Eden L (2004). What is the shape of the multinationalityperformance relationship? Multinational Bus. Rev., 12(1): 89-110. 